\title{
Mechanical Behavior of High Strength Concrete Reinforced with Glass Fiber Reinforced Polymer
}

\section{Mahmoud Mazen Hilles* and Mohammed M Ziara}

Department of Civil Engineering, Islamic University of Gaza, Gaza City, Palestine

\begin{abstract}
Effects of alkali resistant glass fiber reinforced polymer (AR-GFRP) with various proportions on the mechanical behavior of high strength concrete (HSC) were investigated on this study. Concrete mixtures were prepared with various proportions of AR-GFRP typically $0.3,0.6,0.9$, and 1.2 by weight of cement. The mixtures were cast and tested for compressive, splitting tensile and flexural strengths in accordance to ASTM standards. The experimental results showed that the strengths increase as fiber percentage increases; the compressive strength increased from 57.85 to $66.6 \mathrm{MPa}$, the splitting tensile strength increased from 3.06 to $4.92 \mathrm{MPa}$, and the flexural strength increased from 4.84 to $7.27 \mathrm{MPa}$ when fiber percentage increased from 0.0 to 1.2 respectively. In comparison with plain HSC control specimens that showed destructive sudden failure, the formation of cracks that led to failure in the specimens with AR-GFRP was gradual as the fiber percentage increases. Hence it can be concluded that the presence of fibers in the matrix has contributed towards prevent sudden crack formation and thus enhancing concrete ductility.
\end{abstract}

Keywords: HSC; GFRC; AR-GFRP; HSGFRC; Mechanical behavior; Mechanical properties; Mode of failure

\section{Introduction}

It has been recognized that high strength concrete (HSC) has a brittle behavior at ultimate limit state of loading. The addition of closely spaced and uniformly dispersed small fibers to concrete would act as crack arrester and would sub-stantially improve its mechanical behavior and ductility. The addition of fibers results in a product, which has higher flexural and tensile strengths compared with normal concrete [1].

The conventional fiber reinforced concrete (FRC) made by adding fibers in normal strength concrete (NSC) only exhibits an increase in ductility compared with the plain matrix, whereas high strength fiber reinforced concrete (HSFRC) made by adding fibers in HSC exhibits substantial strain hardening type of response which leads to a large improvement in both strength and toughness compared with the plain matrix [2].

Many types of fibers are available in practice; glass fiber reinforced polymer (GFRP) is preferred than other types due to high ratio of surface area to weight and high strength properties to unit cost ratio. However, glass fiber which is originally used in conjunction with cement was found to be affected by alkaline condition of cement. The alkali resistant glass fiber reinforced polymer (AR-GFRP), which is used recently has overcome this defect and can be effectively used in concrete [3].

For new materials like high strength glass fiber reinforced concrete (HSGFRC), studies on mechanical behavior are of paramount important for initializing confidence in engineers. Most of the carried-out research on mechanical behavior of FRC, was made with steel, carbon, and natural fibers. However, few attempts were made with glass fibers. In addition, the literature indicates that most of available studies were made with normal strength concrete (NSC) reinforced with insufficient proportions of glass fibers. Therefore, the undertaken study was conducted to investigate the mechanical behavior of HSC reinforced with various percentages of glass fibers.

The aim of this research is to study the effect of the addition of ARGFRP with various proportions on the mechanical behavior of HSC. Strength characteristics and mode of failure of HSGFRC were compared with plain HSC, by performing laboratory tests on compressive strength, splitting tensile strength, flexural strength, and density.

\section{Materials and Methods}

\section{Materials}

HSGFRC constituent materials used in this research include ordinary Portland cement, course aggregate, fine aggregate, normal range water reducer (NRWR) and GFRP. Proportions of these constituent materials have been chosen carefully to optimize the packing density of the mixture. Ordinary Portland cement CEM II 42.5R was used. The cement met the requirements of ASTM C150 specifications [4]. According to the local market surveying, the available fine aggregate is dune sand type which is finer than required by standard specifications of ASTM C33 [5] and its gradation does not fall within the limits. However, many researchers mentioned that the role of FM and gradation of the fine aggregate in HSC is not as crucial as in conventional strength mixtures [6,7]. The grain distribution of fine aggregate is shown in Table 1. The coarse aggregate was natural crushed lime stone of $12.5 \mathrm{~mm}$ nominal maximum size. The sieve analysis of the coarse aggregate according to ASTM C33 [5] is shown in Figure 1. The specific gravities of coarse and fine aggregates were 2.66 and 2.63 respectively. NRWR confirming

\begin{tabular}{|c|c|}
\hline Sieve Size $\mathbf{( m m})$ & Passing (\%) \\
\hline 4.75 & 100 \\
\hline 2.36 & 100 \\
\hline 1.18 & 95.99 \\
\hline 0.6 & 87.33 \\
\hline 0.425 & 73.14 \\
\hline 0.3 & 39.33 \\
\hline 0.15 & 1.5 \\
\hline 0.075 & 0 \\
\hline Fineness Modulus (FM) & 1.75 \\
\hline
\end{tabular}

Table 1: Grain distribution of fine aggregate.

*Corresponding author: Mahmoud Mazen Hilles, Department of Civil Engineering Islamic University of Gaza, P.O.Box 108, Rimal St. Gaza City, Palestine, Tel: +970 8 2644400; Fax: +970 8 2644800; E-mail: mmh28@windowslive.com

Received May 24, 2017; Accepted July 02, 2018; Published July 06, 2018

Citation: Hilles MM, Ziara MM (2018) Mechanical Behavior of High Strength Concrete Reinforced with Glass Fiber Reinforced Polymer. J Civil Environ Eng 8: 318. doi: 10.4172/2165-784X.1000318

Copyright: $\odot 2018$ Hilles MM, et al. This is an open-access article distributed under the terms of the Creative Commons Attribution License, which permits unrestricted use, distribution, and reproduction in any medium, provided the original author and source are credited. 
ASTM C494 [6] Type A specification was used with dosage of $2 \mathrm{Lit} . / \mathrm{m}^{3}$ according to manufacturer's suggestion. According to manufacture data sheet, the properties of AR-GFRP used are shown in Table 2.

\section{Mix proportioning}

The reference concrete mix (without GFRP) was developed on a trial and error basis to obtain 28-day cylinder compressive strength for design of $50 \mathrm{MPa}$. The first trail mixture was based on Kosmatka et al. [8], then modifications were applied to obtain the best determinable mix design proportions that achieved the target design strength.

Five fiber percentages were used, i.e. 0.0, 0.3, 0.6, 0.9, and 1.2 by weight of cement. The amount of fiber added in HSC mixtures was replaced by coarse aggregate. Accordingly, the five mixes shown in Table 3 were used to evaluate the effect of AR-GFRP on the mechanical behavior of plain HSC. These percentages were chosen in a range that can give better observation and evaluation on the mechanical behavior of HSGFRC when contain a small amount of fiber and when contain a large amount of fiber. For the reference mixture M50 F0 (without fibers), mixing procedures was applied in accordance with ASTM C192 [7]. However, for addition of the glass fibers; special attention was applied. The glass fibers were always added last and mixed for the minimum time required to achieve uniform dispersion and to prevent their damage by excessive mixing.

\section{Test specimens and method}

Compressive strength, splitting tensile strength, flexural strength, and density tests were carried out to evaluate the strength properties of HSGFRC using MATEST C104 Servo Plus with a capacity of $2000 \mathrm{KN}$. Each test was carried out at ages 7 and 28 days, except for the density which was deter-mined at 28 days. Cylinder specimens of $150 \times 300 \mathrm{~mm}$ were prepared for testing the adopted HSC mix proportions that carried out in the trial mix stage which achieve the target design strength at 28 days of $50 \mathrm{MPa}$. The test of compressive strength was made according to ASTM C39 [8]. The specimens were loaded under compressing at a constant stroke rate of $1.4 \mathrm{MPa} / \mathrm{min}$. confirming to the standard requirements. Cube specimens of $150 \times 150 \times 150 \mathrm{~mm}$ were prepared for compressive strength test and density. The test of compressive strength was made according to BS 1881, Part 108 standard test method [9]. The specimens were loaded at a constant stroke rate of $0.34 \mathrm{MPa} /$

\begin{tabular}{|c|c|}
\hline Fiber Properties & Quantity \\
\hline Fiber Length & Hybrid 8 to $30 \mathrm{~mm}$ \\
\hline Diameter & $14 \mu$ \\
\hline Density & $2.7 \mathrm{t} / \mathrm{m}^{3}$ \\
\hline Modulus of Elasticity & $72 \mathrm{GPa}$ \\
\hline Tensile Strength & $1,700 \mathrm{MPa}$ \\
\hline Chemical Resistance & Very high \\
\hline Electrical Conductivity & Very low \\
\hline Softening Point & $860^{\circ} \mathrm{C}$ \\
\hline Zro $_{2}$ Content & $15 \%$ to $20 \%$ \\
\hline
\end{tabular}

Table 2: Properties of AR-GFRP.

\begin{tabular}{|c|c|c|c|c|c|c|}
\hline IN & $\begin{array}{c}\text { \%AR-GFRP by } \\
\text { Weight of Cement }\end{array}$ & $\mathbf{C}(\mathbf{k g})$ & FA (kg) & CA (kg) & NRWR (Lit.) & W/C \\
\hline M50 F0 & 0 & 600 & 484 & 1068 & 2 & 0.4 \\
\hline M50 F1 & 0.3 & 600 & 484 & 1066 & 2 & 0.4 \\
\hline M50 F2 & 0.6 & 600 & 484 & 1064 & 2 & 0.4 \\
\hline M50 F3 & 0.9 & 600 & 484 & 1062.5 & 2 & 0.4 \\
\hline M50 F4 & 1.2 & 600 & 484 & 1060.5 & 2 & 0.4 \\
\hline
\end{tabular}

Table 3: HSGFRC Mixtures for $1 \mathrm{~m}^{3}$ of Concrete. sec. confirming the standard requirements. Cylinder specimens of 150 $\times 300 \mathrm{~mm}$ were prepared for splitting tensile strength test in accordance to ASTM C496 standard test method [10]. The specimens were loaded at a constant stroke rate of $1.4 \mathrm{MPa} / \mathrm{min}$. confirming the standard requirements. Prism speimens of $100 \times 100 \times 500 \mathrm{~mm}$ were prepared for flexural strength test using center-point loading in accordance to ASTM C293 [11]. The specimens were loaded so that the extreme fiber stress increases at rate of $1 \mathrm{MPa} / \mathrm{min}$. confirming the standard requirements. For each mix, three specimens were made for testing for each test for period of 28 days and two specimens were made for testing for each test for period of 7 days. The mean value of the test results of the specimens was considered as the test result of the experiment.

\section{Test Results and Discussion}

\section{Mix design compressive strength test results}

The average 28 days' compressive strength of three-cylinder specimens for the adopted HSC mix proportions that carried out in the trial mix stage was $51.15 \mathrm{MPa}$ which obviously achieve the target design strength of $50 \mathrm{MPa}$.

\section{Size effect}

The results of 7 and 28 days' compressive strength are shown in Table 4 . The average 28 days' cylinder compressive strength of plain HSC specimens (without fiber) obtained from adopted mix proportion was equal to $51.149 \mathrm{MPa}$, however, the average 28 days' cube compressive strength of plain HSC specimens as shown in Table 4 was equal to $57.85 \mathrm{MPa}$. Therefore, the ratio of cylinder to cube compressive strength was equal to 0.88 which is obviously higher than for normal strength grade. It should be mentioned that this ratio increases as concrete strength increases until approaching 1 for ultrahigh strength concrete [12]. The compression test assumes a state of pure, uniaxial compression. Which is untrue because of the friction between the ends of the specimen and the bearing plates of the test machine. Through friction, the bearing plates act to restrain the lateral expansion of the ends of the specimen and to introduce a lateral confining pressure near the specimen ends. This confining pressure is greatest right at the specimen end and gradually dies out forward the middle of the specimen [12]. It is believed that the restraining effect of the bearing plates of the testing machine may extends over the entire height of a cube specimen, however, it leaves unaffected part of cylinder specimen. It is, therefore, to be expected that the strength of cubes specimen is greater than for cylinder specimen made from the same concrete. For NSC, the ratio of cylinder to cube compressive strength is around 0.8 , but there is no simple relation between the strength of the specimens of two shapes. However, for HSC, the effect of specimen's size and shape on the compressive strength is insignificant as for NSC. The ratio of cylinder to cube compressive strength increases strongly with an increase in strength and is nearly one at strength of more than $100 \mathrm{MPa}$ [13]. This increasing in the ratio can be explained such that the lateral expansion in HSC is small and thus the plate confining effect will be insignificant

\begin{tabular}{|c|c|c|c|c|c|c|}
\hline & & \multicolumn{4}{|c|}{ Average Compressive Strength } & \% Increase Over the \\
IN & $\begin{array}{c}\text { \% } \\
\text { GFRP }\end{array}$ & \multicolumn{7}{|c|}{$\begin{array}{c}\mathbf{7} \\
\text { Days }\end{array}$} & $\begin{array}{c}\mathbf{2 8} \\
\text { Days }\end{array}$ & $\begin{array}{c}\text { S 28 } \\
\text { Days }\end{array}$ & $\begin{array}{c}\text { CV \% 28 } \\
\text { Days }\end{array}$ & $\begin{array}{c}\text { Reference Mix - 28 } \\
\text { Days }\end{array}$ \\
\hline M50 F0 & 0 & 46.1 & 57.9 & 1.49 & 2.58 & 0 \\
\hline M50 F1 & 0.3 & 48 & 61.1 & 2.48 & 4.06 & 5.238 \\
\hline M50 F2 & 0.6 & 50.7 & 66 & 2.86 & 4.33 & 12.36 \\
\hline M50 F3 & 0.9 & 49.7 & 66.3 & 1.95 & 2.94 & 12.79 \\
\hline M50 F4 & 1.2 & 49.6 & 66.6 & 2.6 & 3.9 & 13.14 \\
\hline
\end{tabular}

Table 4: Compressive strength test results. 
in both the cube and the cylinder. Both specimens will be subjected in this case to uniaxial state of stress.

\section{Effect of AR-GFRP on the compressive strength of HSC}

From Table 4, it is observed that with increase in fiber percentage, the compressive strength also increases. As shown in Figure 2, the 28 days' compressive strength increases sharply from 57.85 to $66.01 \mathrm{MPa}$ with increase in fiber percentage from 0.0 to 0.6 respectively. Then, a very slight increase is observed in the compressive strength from 66.01 to $66.6 \mathrm{MPa}$ when fiber percentage increases from 0.6 to 1.2 respectively. In general, as shown in Figure 3, the percentage of increase over the reference mix at fiber percentage of 0.6 and 1.2 is 12.36 and 13.14 percent respectively, hence it is established that fiber percentage of 0.6 can be consider the optimum value of fiber addition for compressive strength enhancement since the difference between those values of fiber percentage is insignificant.

The behavior shown in Figure 2, can be explained such that according to $\mathrm{Li}$ [14], the reinforcement provided by fibers can work at both a micro and macro levels. At a micro level fiber arrest the development of micro cracks. The ability of the fiber to control micro cracking growth depends mainly on the number of fibers. Whereas at a macro level, fibers control crack opening and increasing the energy absorption capacity of the composite. Hence, a higher number of fibers in the matrix leads to a higher probability of a micro crack being in-tercepted by a fiber leading to higher compressive strengths as can be seen in Figure 2 where a sharp increase in the compressive strength is observed as fiber percentage in-crease from 0.0 to 0.6 . Whereas at a macro level, the mode of failure will be enhanced due to the great amount of energy that consumed by fibers and due to postponing the formation of the first major crack in the matrix. On the other hand, fiber addition causes some perturbation of the matrix and appear strongly at high percentage of fibers, which can result in higher voids during the micro level due to fiber de-bonding and pullout process as long as there is no fiber fracture. When the macro level starts, voids can be seen as defects where macro cracking starts. In addition, as the amount of fiber exceeded the optimal value, larger surface area of coarse aggregate particles will be surrounded be fibers which is soft polymeric material could weaken the aggregate interlock thereby reducing the compressive strength of the concrete. It is safe then to say that the influence of fibers on the compressive strength at higher percentages could not enhance or increase the compressive strength as discussed and as can be seen in Figure 2 where a very slight increase is observed at fiber percentage from 0.6 to 1.2.

Test result show good agreement with other researchers studied the effect of addition of GFRP on structural concrete, Swami et al. [15] and Ghorpade [16] show that the concrete compressive strength can increased obviously when small amount of fiber used, however, there was no additional significant enhancement in compressive strength when fiber percentage increased upper the optimum value as shown in Figure 4 Ghorpade -whose use very high strength concrete (VHSC) to study the effect of addition of GFRP- show that the optimum amount of fiber addition can be achieved at 1 percent, while when using HSC -such this research- the optimum amount of fiber addition can be achieved at 0.6 percent, frequently, using lower strength -such Swami- the optimum amount of fiber addition could decrease to 0.3 percent. Hence, it was established that as concrete strength increase, the optimum amount of fiber addition for compressive strength enhancement also increase as shown in Figure 4.

\section{Effect of AR-GFRP on the strength gain with age of HSC}

Figure 5 illustrates the strength gain with age for each mix. Figure 6 illustrates the relative strength gain at 7 and 28 days with percentage AR-GFRP. About Figure 6, it is obvious that the ratio of 7 days to 28

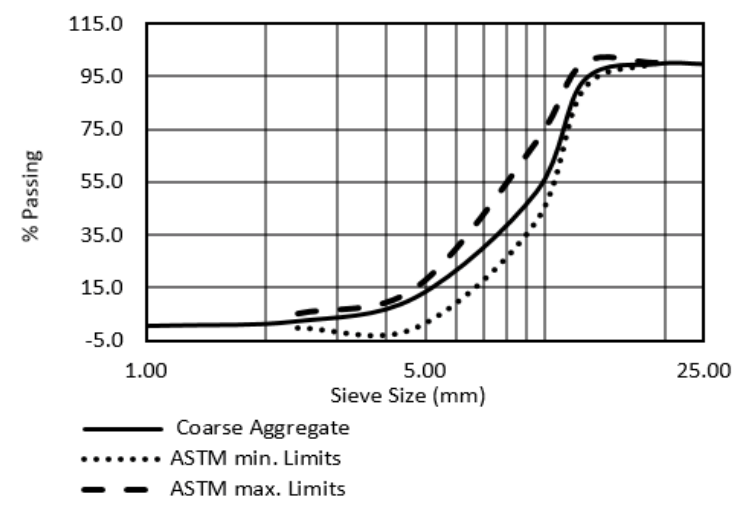

Figure 1: Coarse aggregate sieve analysis according to ASTM C33 [5]

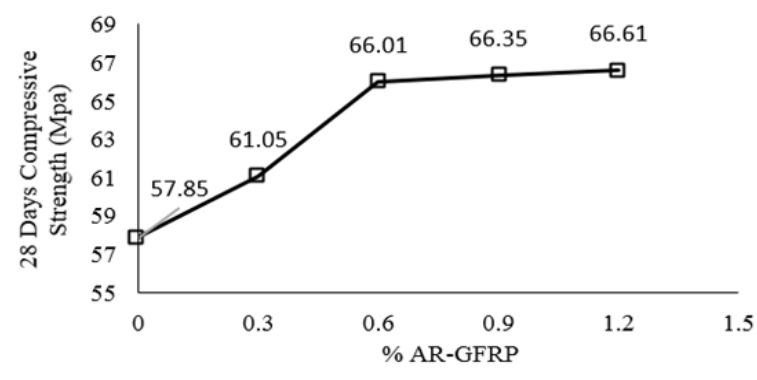

Figure 2: Effect of AR-GFRP on 28 days compressive strength of HSC.

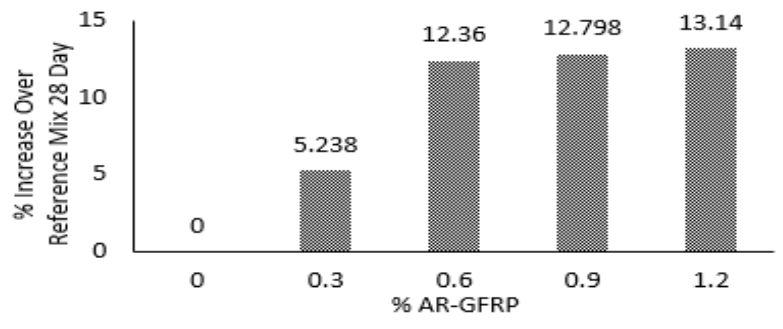

Figure 3: The percentage of increase in compressive strength over the reference mix due to addition of AR-GFRP on HSC.

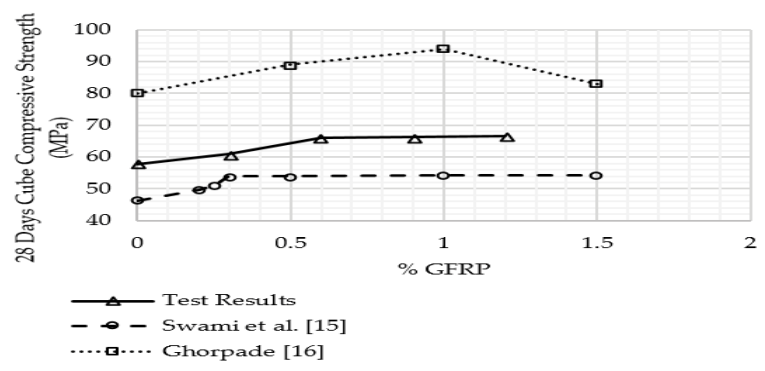

Figure 4: Comparisons of compressive strength test results with other related researches. 


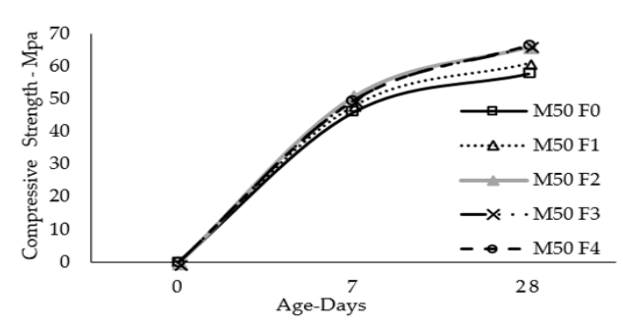

Figure 5: Effect of AR-GFRP on the strength gain with age of HSC.

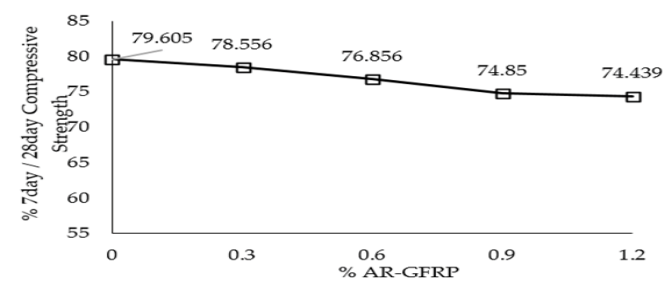

Figure 6: Effect of AR-GFRP on percentage 7days/28days compressive strength.

days' compressive strength for the reference mix (M50 F0) is higher than for normal strength grade, typically 79.6 percent. However, according to ACI committee 363 [17], it has been recognized that HSC shows a higher rate of strength gain at early ages compared to NSC. The higher rate of strength development of HSC at early ages is caused by an increase in the internal curing temperature in the concrete mixtures due to a higher heat of hydration and shorter distance between hydrated particles due to low water-cement ratio. However, as shown in Figure 6, the ratio of 7 days to 28 days' compressive strength has decreased from 79.6 to 74.43 as fiber percentage increased from 0.0 to 1.2 , respectively. This can be explained by that fibers may have absorbed part of increased temperature and can make the distance between hydrated particles wider, which will in turn result in less internal curing temperature in the concrete mixtures.

\section{Effect of AR-GFRP on the density of HSC}

Figure 7 shows the effect of AR-GFRP on the concrete den-sity. It is observed that with increase in fiber percentage, the density increases very slightly. This can be explained due to the extremely light weight and high ratio of surface area to weight of AR-GFRP.

\section{Crack pattern and mode of failure during compressive strength test}

Observation of specimens during compressive strength tests showed that in the case of plain HSC specimens; Figure 8, the failure was sudden, brittle and destructive with loud sound. However, with addition of fiber by 0.3 percent on HSC specimens, the failure became normal similar to normal strength concrete as shown in Figure 9. HSC specimens with 0.6 and 0.9 fiber percentage showed finer cracks and less dispersion compared with HSC specimens with 0.3 fiber percentage as shown Figures 10 and 11, respectively. At highest fiber percentage of 1.2, the specimens after failure remained intact as shown in Figure 12 and the cracks were extremely fine.

In conclusion, it is observed that as fiber percentage increases, failure takes place gradually with the formation of cracks and can arrest sudden crack formation. Moreover, although the higher fiber percentage could not enhance the compressive strength -as explained before- at a macro level, fibers at higher percentages can control crack opening, consume a great amount of energy, and postponing the formation of the first major crack in the matrix, hence changing the failure mode from brittle to quasi-ductile.

\section{Effect of AR-GFRP on the splitting tensile strength of HSC}

Table 5 show the results of 7 and 28 days splitting tensile strength, respectively. According to ACI Committee 363 [17], Equation (1) was recommended for the prediction of the splitting tensile strength $\left(F_{s p}\right)$ of HSC with 28 days' cylinder compressive strength $\left(f_{c}^{\prime}\right)$ within 21 to 83 $\mathrm{MPa}$.

$$
F_{s p}=0.59 \sqrt{f c^{\prime}}
$$

The 28 days' cylinder compressive strength of plain HSC was equals to $51.149 \mathrm{MPa}$; which makes the predicted splitting tensile strength $F_{s p}$ using Equation (1) equals to $4.21 \mathrm{MPa}$. This value is very close with the average experimental value of plain HSC specimens (M50 F0) of 4.12 MPa shown in Table 5. The difference is $2.1 \%$ only! showing good agreement.

It is observed from Table 5 that with increase in fiber percentage, the splitting tensile strength increases significantly. As shown in Figure 13, the splitting tensile strength increased from 3.06 to $4.92 \mathrm{MPa}$ with the increase in the fiber percentage from 0.0 to 1.2 , respectively for 7 days. For 28 days, the strengths increased from 4.12 to $6.7 \mathrm{MPa}$ when the fiber percentage increased from 0.0 to 1.2 , respectively. It is observed from Figure 14 that, the percentage of increase in the splitting tensile strength over the reference mix due to addition of fibers is much higher than for the compressive strength. Moreover, the increasing trend in splitting tensile strength due to addition of fibers continued ascending until the highest value of $6.73 \mathrm{MPa}$ at (28 Days) at the highest fiber percentage of 1.2 as shown in Figure 13.

In comparison with the increase in compressive strength Figure 2 shows continuous ascending just until 0.6 fiber percentage and then at fiber percentage from 0.6 to 1.2 , the increasing rate reduced slightly. This difference between the increasing mode of compressive strength and splitting tensile strength curves shown in Figures 2 and 13 can be explained simply that the defects that caused by higher fiber

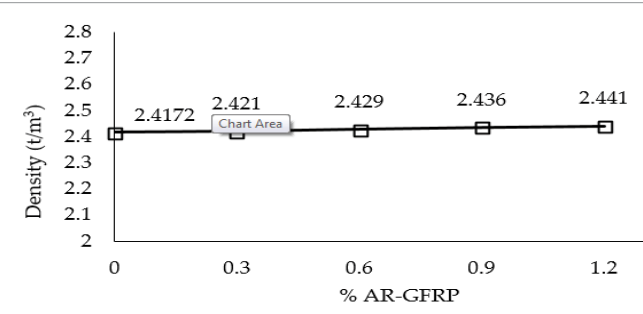

Figure 7: Effect of AR-GFRP on density of HSC.

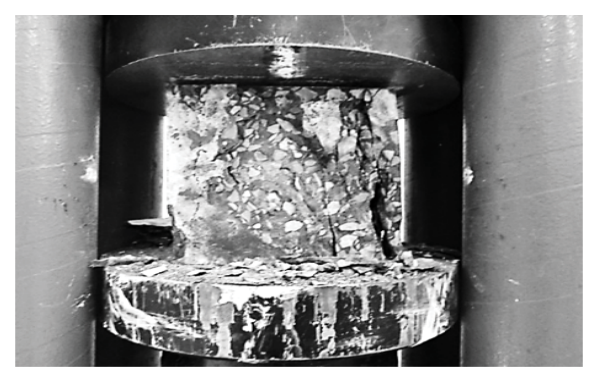

Figure 8: Mode of failure and crack pattern of plain HSC specimens (Without Fiber). 


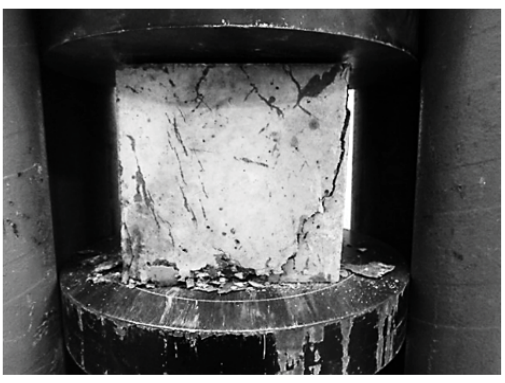

(a)

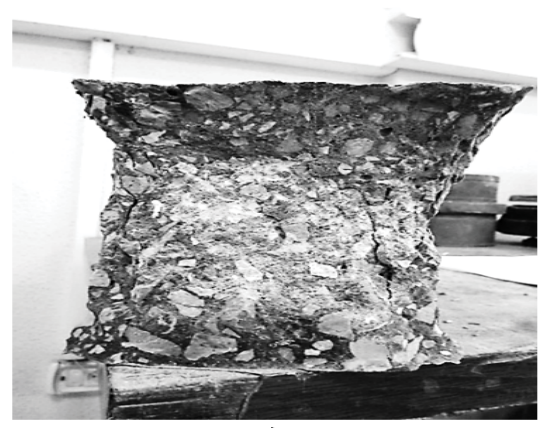

(b)

Figure 9(a and $\mathbf{b})$ : Mode of failure and crack pattern of HSC specimens with 0.3 fibre percentage.

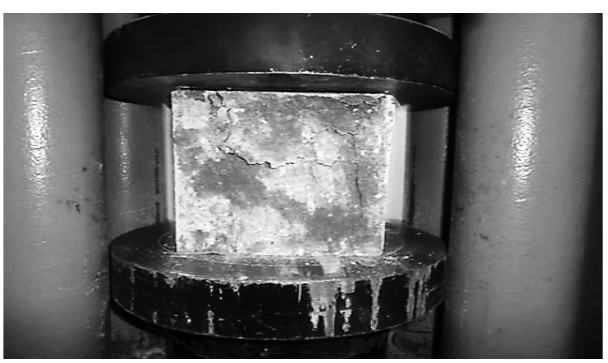

Figure 10: Mode of failure and crack pattern of HSC specimens with 0.6 fibre percentage.

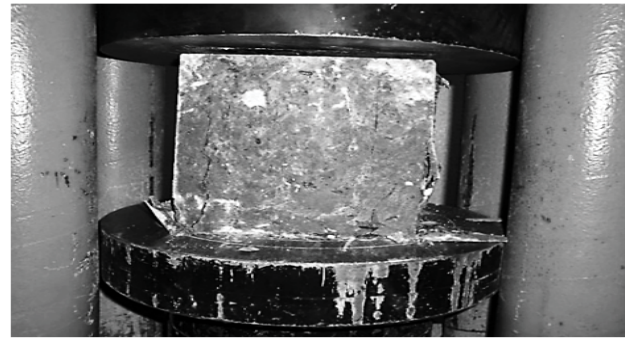

Figure 11: Mode of failure and crack pattern of HSC specimens with 0.9 fibre percentage.

percentages during the micro level, which are as discussed before, the voids due to fiber de-bonding and pullout process, and the weakness of the aggregate interlock due to softening and polymeric characteristic of fibers, appear strongly when the concrete fail due to compressive stress. While in splitting tensile test, although the cylinder specimen subjected to compressive load, the specimen fails due to the induced tensile stresses before reach its ultimate compressive strength capacity (i.e. for

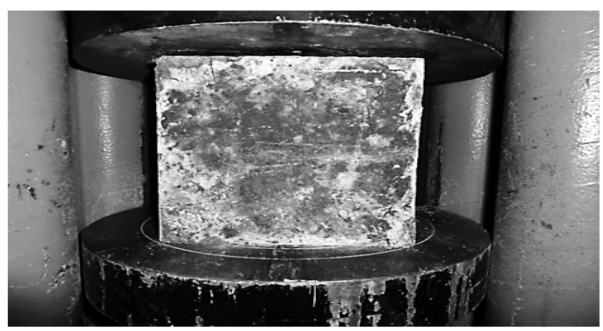

Figure 12: Mode of failure and crack pattern of HSC specimens with 1.2 fibre percentage.

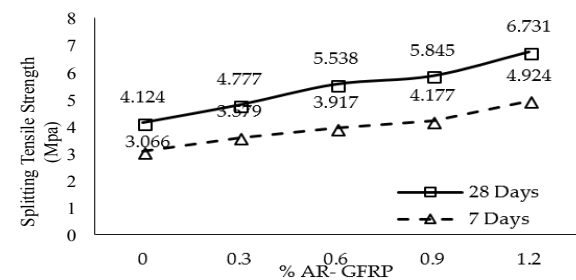

Figure 13: Effect of AR-GFRP on splitting tensile strength of HSC.

\begin{tabular}{|c|c|c|c|c|c|c|}
\hline \multirow{2}{*}{ IN } & \multirow{2}{*}{$\%$ GFRP } & \multicolumn{4}{|c|}{$\begin{array}{l}\text { Average Split Tensile Strength } \\
\text { (MPa) }\end{array}$} & \multirow{2}{*}{$\begin{array}{c}\text { \% Increase Over the } \\
\text { Reference Mix (28 } \\
\text { Day) }\end{array}$} \\
\hline & & $\begin{array}{c}7 \\
\text { Days }\end{array}$ & $\begin{array}{c}28 \\
\text { Days }\end{array}$ & S 28 Day & $\begin{array}{l}\text { CV \% } \\
28 \text { Day }\end{array}$ & \\
\hline M50 F0 & 0 & 3.07 & 4.12 & 0.22 & 5.5 & 0 \\
\hline M50 F1 & 0.3 & 3.58 & 4.78 & 0.55 & 11.6 & 15.83 \\
\hline M50 F2 & 0.6 & 3.92 & 5.54 & 0.33 & 6.1 & 34.28 \\
\hline M50 F3 & 0.9 & 4.18 & 5.85 & 0.45 & 7.8 & 41.73 \\
\hline M50 F4 & 1.2 & 4.92 & 6.73 & 0.39 & 5.8 & 63.22 \\
\hline
\end{tabular}

Table 5: Splitting tensile strength test results.

the same mixture of $\mathrm{M} 50 \mathrm{~F} 4$, in the compression test, the maximum average applied compressive load at 28 days is $1505.4 \mathrm{KN}$. While in the splitting tensile test, the maximum average applied compressive load at 28 days is only $473.18 \mathrm{KN}$ ).

It is safe then to say that with higher percentage of fibers, according to $\mathrm{Li}[16]$ it is possible that micro cracks formed in the matrix at micro level will be stabilized due to the interaction between the matrix and fibers through bonding, hence postponing the formation of the first major crack in the matrix. Thus, the apparent tensile strength of matrix can be increased. Hence it is established that AR-GFRP inclusion in HSC mixtures is more powerful for enhancing the tensile strength than compressive strength.

Test result show good agreement with Swami et al. [15]. and Ghorpade [16] who showed that the concrete splitting tensile strength can be increased significantly with addition of glass fiber even when large amount was used. However, Ghorpade who used VHSC, reported that the splitting tensile strength was de-creased at fiber percentage larger than 1 percent as shown in Figure 15.

\section{Crack pattern and mode of failure during splitting tensile strength test}

Observations of specimens during splitting tensile strength test showed in the case of plain HSC that the failure was brittle and occurred by sudden complete splitting accmpained by loud sound, 
Figure 16. With addition of fiber by 0.3 percent on HSC specimens, the mode of failure remained sudden similar to plain HSC specimens as shown in Figure 17. However, HSC specimens with 0.6 and 0.9 fiber percentages showed less sudden splitting failure and remained intact as shown in Figures 18 and 19. At highest fiber percentage of 1.2, the HSC specimens remained standing after failure and the crack was fine as shown in Figure 20. In conclusion, as fiber percentage increased the splitting crack occurred progressively, arrested sudden crack formation, and overcame the brittle characteristic of HSC.

\section{Effect of AR-GFRP on the flexural strength (Modulus of Rapture, $F_{r}$ ) of HSC}

The results of 7 and 28 days' flexural strengths (modulus of rapture, Fr) are shown in Table 6. According to ACI Committee $363[17,18]$, Equation. 2 was recommended for the prediction of $F_{r}$ of HSC with 28 days' cylinder compressive strength $f_{c}^{\prime}$ within 21 to $83 \mathrm{MPa}$.

$$
F_{r}=0.94 \sqrt{f c^{\prime}}
$$

The 28 days' cylinder compressive strength of plain HSC (without fiber) was equals to $51.149 \mathrm{MPa}$. The prediction of $F_{r}$ using Equation 2 equals to $6.72 \mathrm{MPa}$ in comparison with measured average value of 6.35 MPa for plain HSC specimens (M50 F0) shown in Table 6 with a deference of $5.5 \%$ only! showing good agreement.

It is observed from Table 6 that with the increase in fiber percentage, $F_{r}$ increased significantly. As shown in Figure 21, the flexural strength increased continuously from 4.84 to $7.27 \mathrm{MPa}$ with increase in fiber percentage from 0.0 to 1.2 respectively for 7 days, and 6.35 to $9.68 \mathrm{MPa}$ when fiber percentage increase from 0.0 to 1.2 respectively for 28 days.

Therefore, it concluded that the percentage of increase in the flexural strength over the reference mix due to addition of fibers is

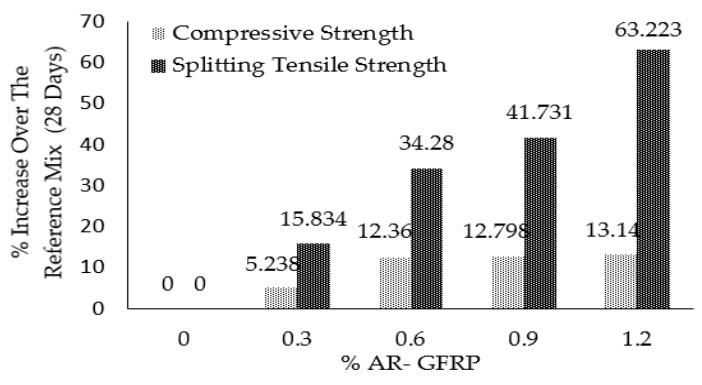

Figure 14: The percentage of increase over the reference mix due to addition of AR-GFRP on HSC: Comparison between compressive strength and splitting tensile strength.

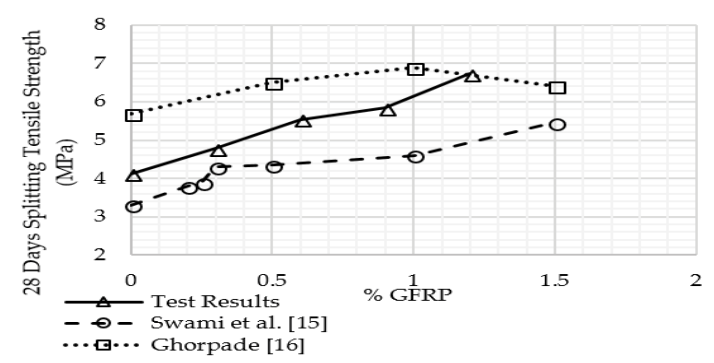

Figure 15: Comparisons of splitting tensile strength test results with other related researches.

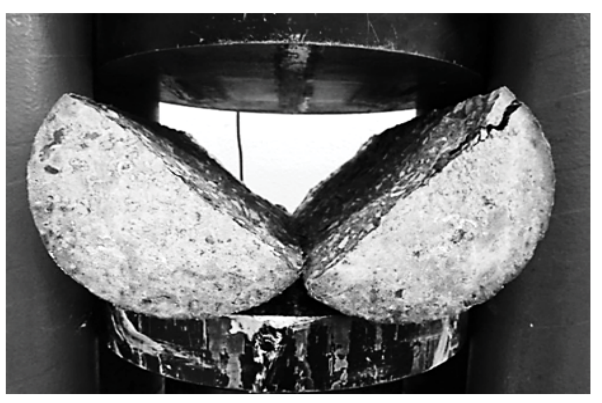

Figure 16: Mode of failure of plain HSC specimens (Without Fiber)

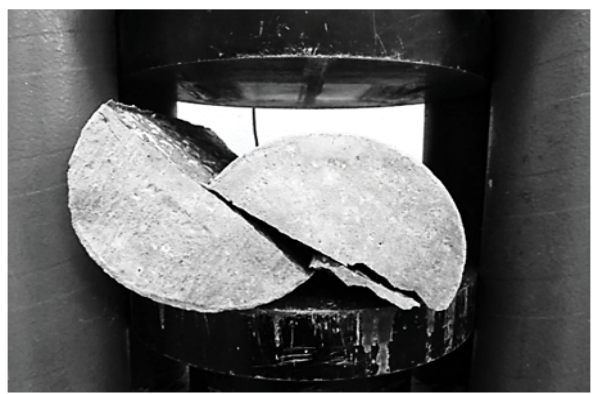

Figure 17: Mode of failure of HSC specimens with 0.3 fibre percentage.

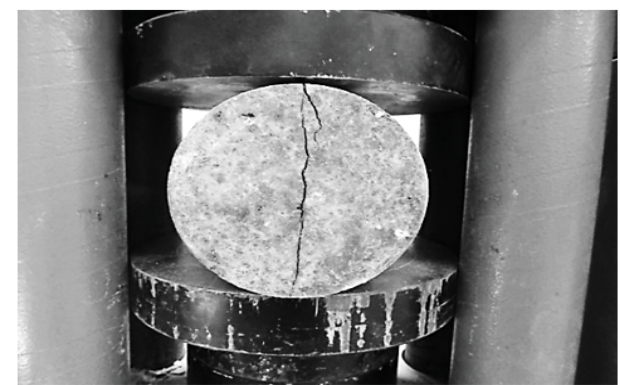

Figure 18: Mode of failure and crack pattern of HSC specimens with 0.6 fibre percentage.

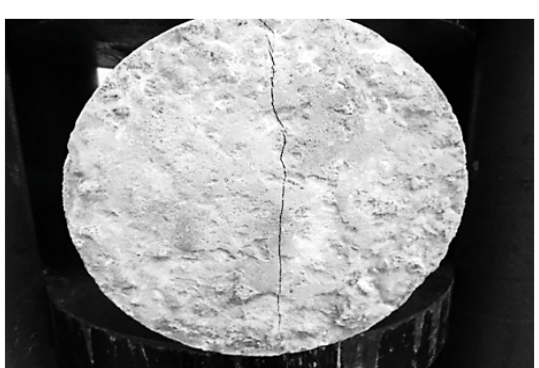

Figure 19: Mode of failure and crack pattern of HSC specimens with 0.9 fibre percentage.

much higher than for the compressive strength; but little less than for splitting tensile strength, except at 0.3 fiber percentage where flexural strength shows the highest percentage of increase as shown in Figure 22. The rate of increasing in flexural strength due to addition of fibers is the same as for splitting tensile strength, which was also ascending until 


\begin{tabular}{|c|c|c|c|c|c|c|}
\hline \multirow{2}{*}{ IN } & \multirow{2}{*}{ \% GFRP } & \multicolumn{4}{|c|}{ Average Flexural Strength (MPa) } & $\begin{array}{c}\text { \% Increase Over } \\
\text { the Reference Mix } \\
\text { (28 Day) }\end{array}$ \\
\hline 7 Days & 28 Days & $\mathbf{S}$ & $\mathbf{C V} \%$ & - \\
\hline M50 F0 & 0 & 4.84 & 6.35 & 1 & 7.79 & -- \\
\hline M50 F1 & 0.3 & 5.28 & 7.53 & 0 & 2.63 & 18.5 \\
\hline M50 F2 & 0.6 & 6.26 & 8.28 & 0 & 3.75 & 30.41 \\
\hline M50 F3 & 0.9 & 6.68 & 8.79 & 0 & 4.24 & 38.35 \\
\hline M50 F4 & 1.2 & 7.27 & 9.68 & 1 & 4.85 & 52.36 \\
\hline
\end{tabular}

Table 6: Flexural strength (Modulus of Rapture) test results.

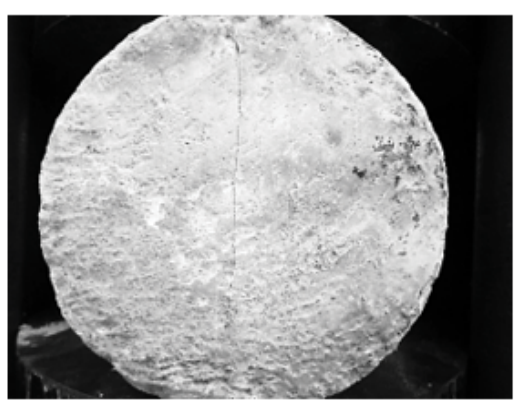

Figure 20: Mode of failure and crack pattern of HSC specimens with 1.2 fibre percentage.

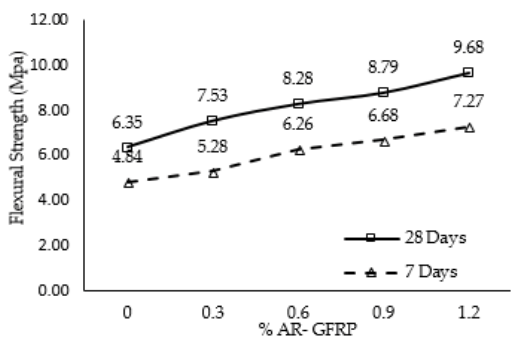

Figure 21: Effect of AR-GFRP on flexural strength (Modulus of Rapture) of HSC.

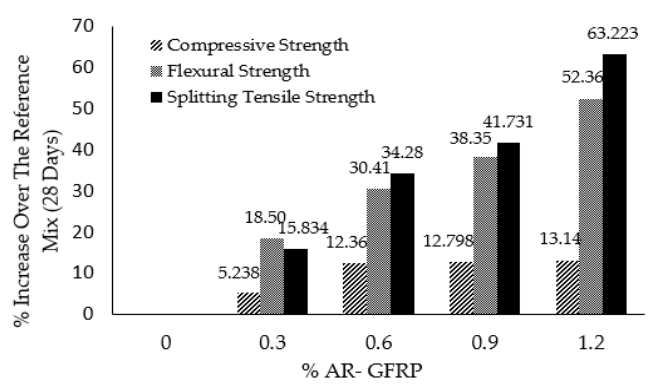

Figure 22: The percentage of increase over the reference mix due to addition of AR-GFRP on HSC: Comparison between compressive, flexural and splitting tensile strength.

the highest value of $9.68 \mathrm{MPa}$ (28 Days) at the highest fiber percentage of 1.2 as shown in Figure 21. In comparison with the increase in the compressive strength, Figure 2 shows continuous ascending just until 0.6 fiber percentage and then at fiber percentage from 0.6 to 1.2 , the increase turned was very slight. This difference between the increasing mode of compressive strength and flexural strength curves shown in Figures 2 and 21 can be explained similarly as for the splitting tensile strength. Hence it is established that AR-GFRP inclusion in HSC mixtures is more effective in enhancing the tensile strength than compression strength.

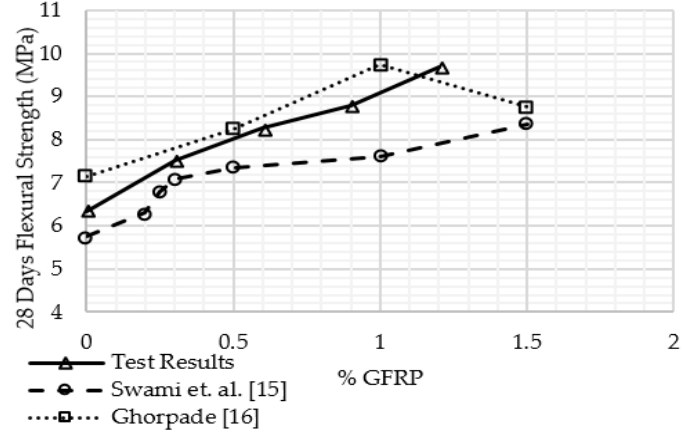

Figure 23: Comparisons of flexural strength test results with other related researches.

Test result show good agreement with Swami et al. [15] and Ghorpade [16] as discussed earlier and as shown in Figure 23 for 1 percent fiber.

\section{Conclusions}

The effects of addition of alkali resistant glass fibers reinforced polymer (AR-GFRP) on the strength and mode of failure of high strength concrete (HSC) up to $51 \mathrm{MPa}$ cylinder compressive strength were experimentally investigated. The following conclusions were made based on the results of compressive strength, splitting tensile strength, flexural strength, and density tests carried out at 7 and 28 .

1. Maximum compressive strength of HSC was obtained at 1.2 percentage of fiber and achieved $13.14 \%$ increase over the reference mix without fibers. With $0.6 \%$ fiber $12.36 \%$ strength increase was recorded.

2. The ratio of 7 days to 28 days' compressive strength decreased from $79.6 \%$ to $74.43 \%$ as fiber percentage increased from 0.0 to 1.2 respectively.

3. The density of HSC increased slightly from 2417 to $2441 \mathrm{~kg} / \mathrm{m}^{3}$ as fiber percentage increased from 0.0 to $1.2 \%$.

4. The splitting tensile strength of HSC increased continuously reaching $63.22 \%$ increase at $1.2 \%$ fiber.

5. The flexural strength (modulus of rapture) increased continuously reaching $52.36 \%$ increase with $1.2 \%$ fiber.

6. It was observed that the percentage of increase in the splitting tensile and flexural strengths over the reference mix due to addition of fibers is much higher than for the compressive strength. Hence, it is established that AR-GFRP inclusion in HSC mixtures is more significant for enhancing the tensile strength than compression strength of HSC.

7. The specimen failure in compressive and splitting tensile strength tests was gradual as fiber percentage increased. On the other hand, the failure of plain HSC specimens was sudden, brittle and completely destruction with sound (Loudly). Hence it is established that the presence of fibers in the matrix has contributed towards prevent sudden crack formation.

8. Test result show good agreement with ACI committee 363 and other relevant researches. 


\section{References}

1. Parra-Montesinos GJ (2005) High-performance fiber-reinforced cement composites: An alternative for seismic design of structures. ACI Struct J 102: $668-675$

2. Buyukozturk O, Lau D (2007) High performance concrete: Fundamentals and application. The International Conference on Developments and Application of Concrete, Istanbul, Turkey.

3. ACl Committee (2002) 544.1R-96: State-of-the-art report on fiber reinforced concrete. $\mathrm{ACl}$.

4. ASTM (2004) ASTM C150: Standard specification of Portland cement.

5. ASTM (2003) ASTM C33: Standard specification for concrete aggregates.

6. ACI Committee 363R (2010) State-of-the-art report on high-strength concrete $\mathrm{ACl}$ Journal Proceedings 81: 364-411.

7. Kosmatka SH, Kerkhoff B, Panarese WC (2003) Design and control of concrete mixtures, EB001, $14^{\text {th }}$ ed. Portland Cement Association.

8. ASTM C494 (2010) Standard specification for chemical admixtures for concrete. ASTM

9. ASTM C192 (2002) Standard practice for making and curing concrete test specimens in the laboratory. ASTM.
10. ASTM C39 (2003) Standard test method for compressive strength of cylindrical concrete specimens. ASTM.

11. BSI (1983) Method for making test cubes from fresh concrete. BS 18881 , Testing concrete, Part 108.

12. ASTM C496 (2004) Standard test method for splitting tensile strength of cylindrical concrete specimens. ASTM.

13. ASTM C293 (2002) Standard test method for flexural strength of concrete (Using simple beam with center-point loading). ASTM.

14. Ziara MM (1993) The influence of confining the compression zone in the design of structural concrete beams, PhD thesis, Heriot-Watt University.

15. Neville AM (2011) Properties of concrete, $5^{\text {th }}$ ed., London: British Library.

16. Li Z (2011) Advanced concrete technology. John Wiley and Sons.

17. Swami B, Asthana A, Masood U (2009) Studies on glass fiber reinforced concrete composites: Strength and behavior. Challenges, Opportunities and Solutions in Structural Engineering and Construction 4: 144-203.

18. Ghorpade VG (2010) An experimental investigation on glass fiber reinforced high performance concrete with silica fume as admixture. In $35^{\text {th }}$ Conference on Our World in Concrete and Structures, Singapore pp: 1-8. 